\title{
Rapid Immobilization of Cellulase onto Graphene Oxide with a Hydrophobic Spacer
}

\author{
Jian Gao ${ }^{1}$, Chun-Liu Lu ${ }^{2}$, Yue Wang ${ }^{3}$, Shuang-Shuang Wang ${ }^{1}$, Jia-Jia Shen ${ }^{2}$, Jiu-Xun Zhang ${ }^{2}$ \\ and Ye-Wang Zhang ${ }^{1,2, *}$ \\ 1 College of Petroleum and Chemical Engineering, Qinzhou University, Qinzhou 535011, China; \\ jgao12@163.com (J.G.); doublewang123@163.com (S.-S.W.) \\ 2 School of Pharmacy, United Pharmaceutical Institute of Jiangsu University and Shandong Tianzhilvye \\ Biotechnology Co. Ltd., Jiangsu University, Zhenjiang 212013, China; luchunliu@outlook.com (C.L.L.); \\ shenjiajia20@163.com (J.-J.S.); zhongshixun661@163.com (J.-X.Z.) \\ 3 School of Pharmacy, Guangxi Medical University, Nanning 530021, China; wyjs69@outlook.com \\ * Correspondence: zhangyewang@ujs.edu.cn; Tel.: +86-511-8503-8201
}

Received: 29 March 2018; Accepted: 25 April 2018; Published: 28 April 2018

\begin{abstract}
A rapid immobilization method for cellulase was developed. Functional graphene oxide was synthesized and grafted with hydrophobic spacer P- $\beta$-sulfuric acid ester ethyl sulfone aniline (SESA) though etherification and diazotization. The functionalized graphene oxide was characterized by Fourier-transform infrared spectroscopy and was used as the carrier for the immobilization of cellulase via covalent binding. The immobilization of cellulase was finished in a very short time (10 min) and very high immobilization yield and efficiency of above $90 \%$ were achieved after optimization. When compared with the free cellulase, thermal and operational stabilities of the immobilized cellulase were improved significantly. At $50{ }^{\circ} \mathrm{C}$, the half-life of the immobilized cellulase $(533 \mathrm{~min})$ was six-fold higher than that of the free cellulase $(89 \mathrm{~min})$. Additionally, the affinity between immobilized cellulase $\left(\mathrm{Km}=2.19 \mathrm{~g} \mathrm{~L}^{-1}\right)$ and substrate was more favorable than that of free cellulase $\left(\mathrm{Km}=3.84 \mathrm{~g} \mathrm{~L}^{-1}\right)$, suggesting the immobilized cellulase has higher catalytic efficiency. The possible immobilization mechanism was proposed. The results strongly indicate that the immobilization is highly efficient and has great potential for the immobilization of other enzymes.
\end{abstract}

Keywords: Graphene hybrid; Surface modification; Cellulase; Immobilization; Stability

\section{Introduction}

Cellulase (E.C 3.2.14) is widely used in the detergent, food, textile, and animal husbandry industries. It can catalyze hydrolyzing $\beta-1,4$-glycosidic bonds of the cellulosic materials to produce glucose that could be further bioconverted into bioethanol [1]. Because cellulosic materials are the most abundant materials and renewable resource in the world, the enzymatic conversion process for biofuels has enormous potential and it been received increasing attentions. However, free cellulase is inevitable to have some drawbacks such as instability, difficult separation from the reaction solution, and low reuse possibility [2]. In order to overcome these shortcomings, immobilization was introduced to improve the performance of cellulase in the biocatalysis, finally to lower the cost to meet the industrial requirements.

In the past few years, cellulase has been immobilized with various methods. Mabarak et al. [3] immobilized cellulase onto multiwall carbon nanotubes with adsorption, and the immobilized enzyme retained $52 \%$ initial activity after six cycles. When compared with the adsorption, covalent binding is more attractive because of the stable covalent bonds formed during the immobilization. Cellulase was covalently immobilized onto magnetic chitosan nanoparticles [4] and polyaniline 
coated polymer microspheres [5], Au-nanoparticles [6], pH-sensitive copolymer [7], and the high stability and reusability of the immobilized enzyme were achieved in these research works.

Immobilization of an enzyme involves the interactions between the enzyme and the carrier [812]. The properties of the carrier play an important role and normally the carrier should have large surface area [13-15]. Graphene with a lamellar structure has many industrial applications due to its unique physical and electronic properties [16]. Graphene oxide (GO), as an oxygenated of graphene, has gained increasing attention for its application in biotechnology because it contains oxygencontaining functional groups such as epoxide, hydroxyl, and carboxylic acids [17]. In addition, GO has some significant advantages, including easy processing, simple production from graphite, and available sites for functionalization [18]. Particularly, GO is afforded an ideal carrier for enzyme immobilization after functionalization, and it has been used as the carrier for immobilization of enzymes [2,19-22].

Appropriate spacer between the enzyme and carrier has been proved to improve the activity of the immobilized enzyme [23]. In the immobilization of trypsin, PEG-diamine, aldehyde dextran, amino dextran, and bovine serum albumin (BSA) spacers were investigated. It is indicated that longer spacers are required for the efficient immobilization of enzymes onto solid carriers because they will minimize steric hindrance and environmental effects that are imposed by the surface properties of the matrices [24]. However, when poly glycine linker was used as the spacer for immobilization of $\alpha$ chymotrypsin onto controlled pore glass and polyethylene glycol copolymer cross-linked with polyacrylamide, it was found that 2 glycines were the optimal linker length [25]. Introducing of appropriate spacer will change the unfavorable surface polarity of the carrier, causing the enzymatic denaturation and preventing the steric hindrance [26].

In the present work, we prepared graphene oxide as carrier for immobilization of cellulase with covalent binding (shown in Scheme 1). The prepared graphene oxide was activated by etherification with p- $\beta$-sulfuric acid ester ethyl sulfone aniline (SESA) as a hydrophobic spacer. The obtained SESAGO was modified by diazotization, and then cellulase was rapidly covalently immobilized onto the activated functional GO. Characterization of the prepared carrier and the final immobilized cellulase were also performed.

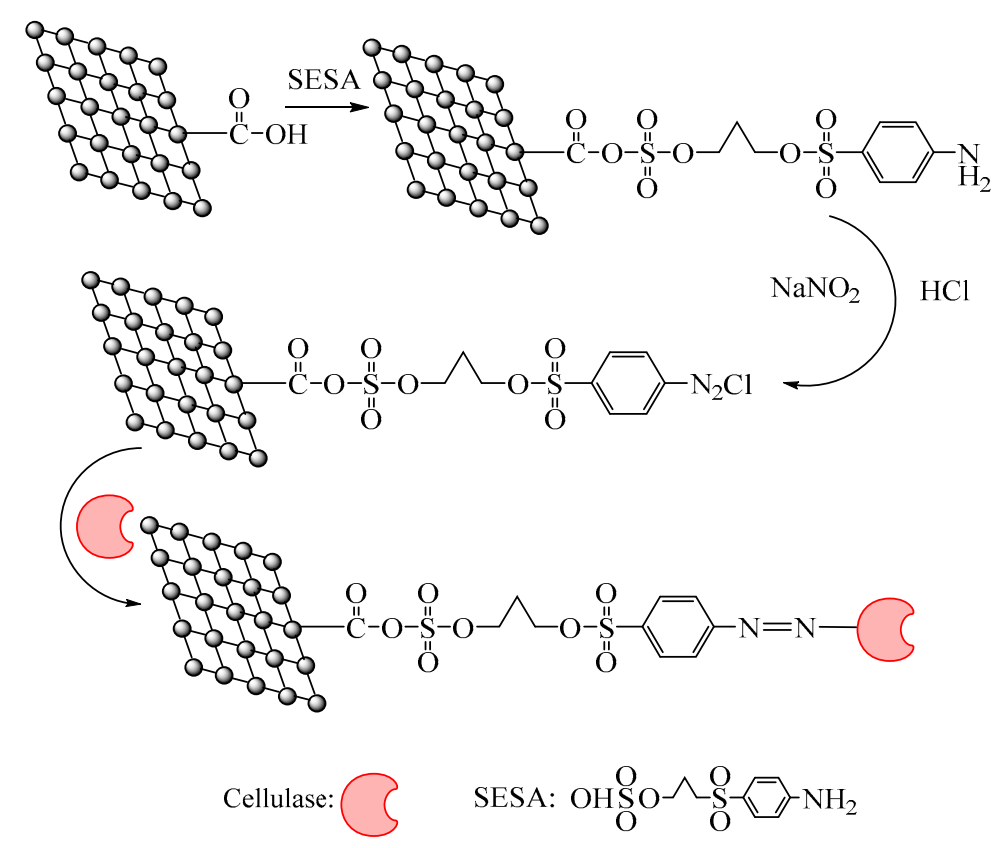

Scheme 1. Schematic description of preparation of functionalized graphene oxide (GO) and immobilization of cellulase. 


\section{Results}

\subsection{Characterization of Activated Graphene Oxide}

The Fourier transform infrared (FTIR) spectra of GO and SESA-GO were presented in Figure 1. As shown in Figure 1a, the characteristic band of carbonyl groups at $\sim 1710 \mathrm{~cm}^{-1}$ corresponding to $\mathrm{v}$ $(\mathrm{C}=\mathrm{O})$ of $-\mathrm{COOH}$ on the $\mathrm{GO}$, and the $\mathrm{C}-\mathrm{O}$ vibration of epoxy groups appeared at $\sim 1052 \mathrm{~cm}^{-1}$ before activation. The peak at $\sim 3383 \mathrm{~cm}^{-1}$ and $\sim 1618 \mathrm{~cm}^{-1}$ corresponded to the $\mathrm{O}-\mathrm{H}$ and $\mathrm{C}=\mathrm{C}$ vibration, respectively. The peak at $\sim 1710 \mathrm{~cm}^{-1}$ in Figure $1 \mathrm{~b}$ disappeared which indicated that $-\mathrm{COOH}$ was modified obviously.

The morphologies of GO and immobilized cellulase were observed by TEM. Figure 2a shows that irregular sheets of GO with some wrinkles which presented a larger surface area. Cellulase molecular were not observed clearly in Figure $2 b$. There is not much difference between Figure 2a,b, indicating that immobilization of cellulase onto the surface of GO did not change the morphology of GO significantly.

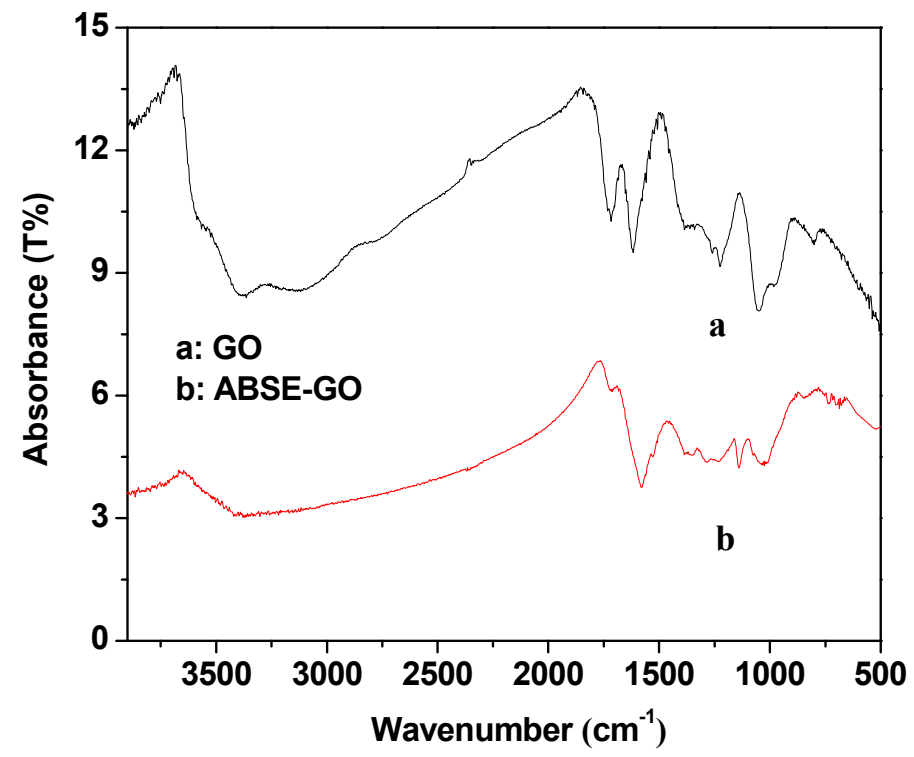

Figure 1. Fourier transform infrared (FTIR) spectra of (a) graphene oxide (GO); and, (b) SESA-GO.
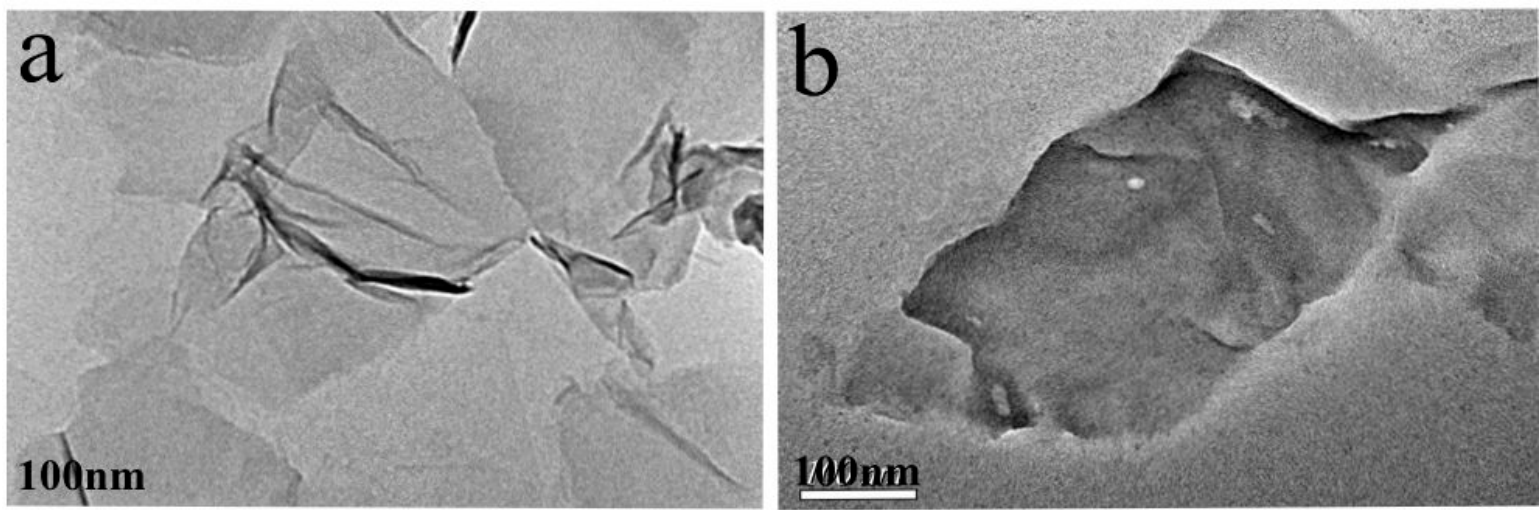

Figure 2. TEM images of (a) GO; (b) immobilized cellulase.

\subsection{Optimization of the Immobilization Conditions}

As shown in Figure 3, the activity of the immobilized enzyme was increased with the increasing $\mathrm{pH}$ in the reactions. The maximum enzyme activity could be obtained when couple $\mathrm{pH}$ was 5.0, which is the isoelectronic point of cellulase. If the $\mathrm{pH}$ was further increased, the activity of immobilized cellulase would be decreased. The immobilization process time course was checked 
from $1 \mathrm{~min}$ to $60 \mathrm{~min}$. As shown in Figure 4, immobilization yield and efficiency were increased rapidly when immobilization time was prolonged from 1 to $10 \mathrm{~min}$. After $10 \mathrm{~min}$, the yield and efficiency reached a plateau, and as time was continued to increase to $60 \mathrm{~min}$, the immobilization yield and the activity recovery changed only a little. Obviously, this reaction was finished within 10 min and the optimal immobilization time was determined as $10 \mathrm{~min}$. The immobilization yield and activity recovery for carrier incubated with cellulase solution of different concentrations were shown in Figure 5. With rising enzyme/support ratio until it reached $4.9 \mathrm{mg} \mathrm{g}^{-1}$, the yield and efficiency were increased gradually. The maximum yield along with the highest efficiency were achieved at $4.9 \mathrm{mg}$ $\mathrm{g}^{-1}$ and the values were $94 \%$ and $91 \%$, respectively. However, further increasing in ratio decreased the immobilization yield and activity recovery linearly, with a similar tendency.

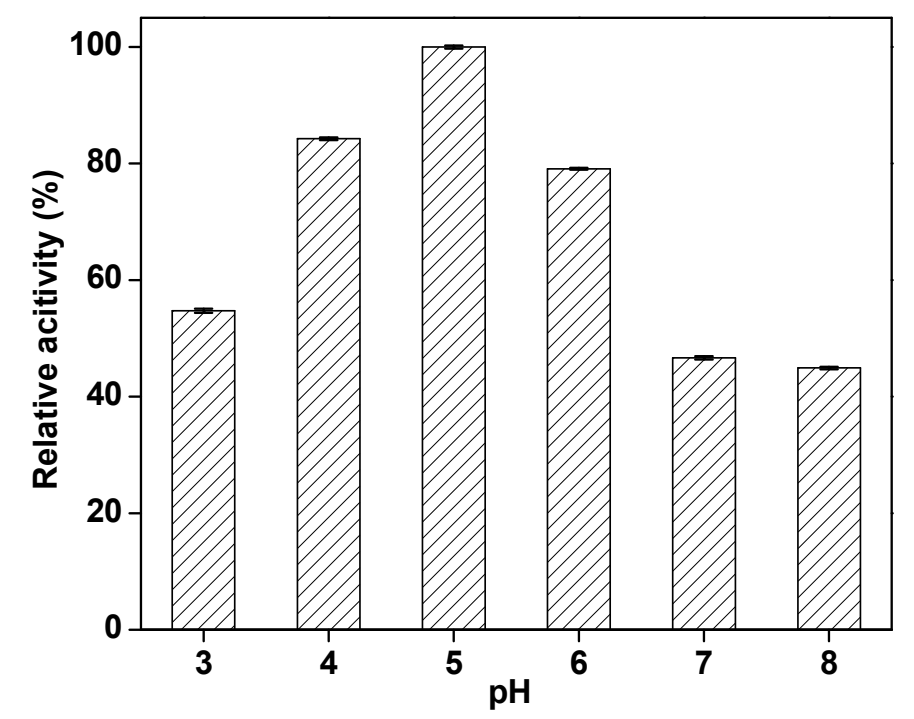

Figure 3. Effect of immobilization $\mathrm{pH}$ value on the immobilization of cellulase.

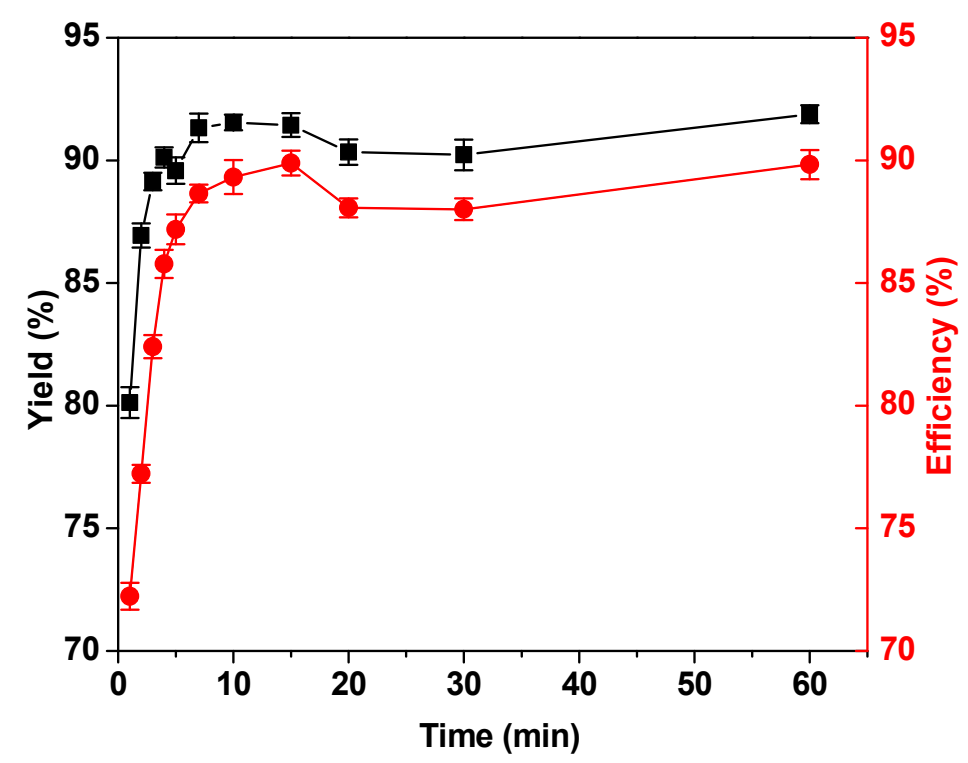

Figure 4. Time course of the immobilization of cellulase onto the functionalized graphene oxide composites. 


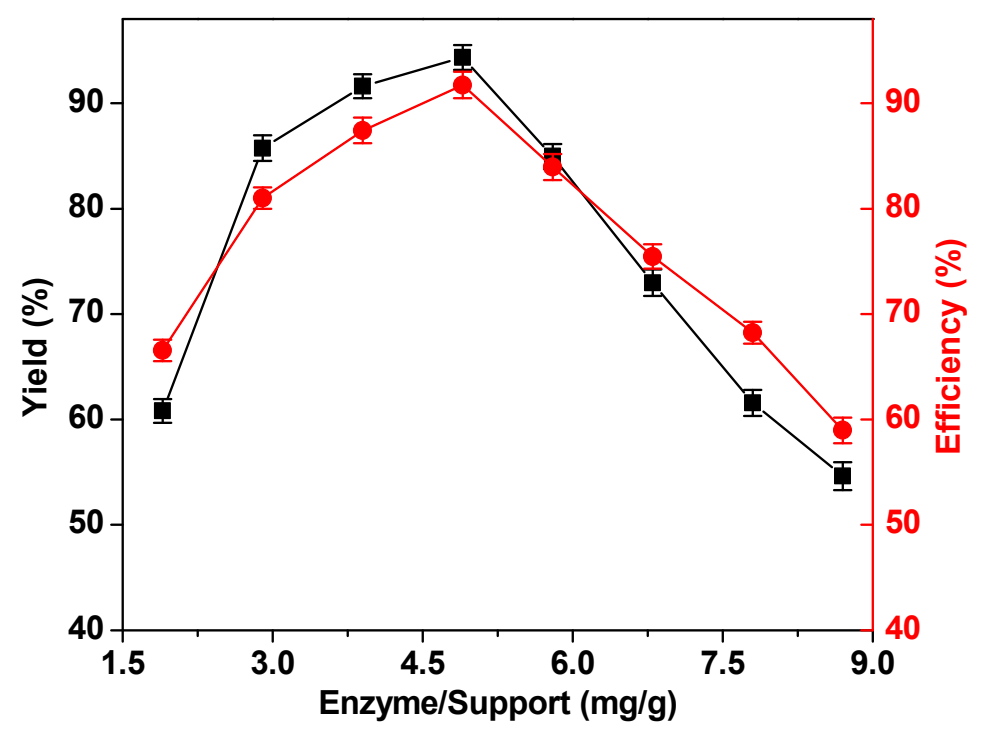

Figure 5. Effect of enzyme/support ratio on the immobilization of cellulase.

\subsection{Characterization of the Immobilized Cellulase}

The relative activity of free and immobilized cellulase were evaluated in the $\mathrm{pH}$ range from 3.0 to 8.0 and 30 to $80^{\circ} \mathrm{C}$ (Figure 6). The maximal activities of the free and immobilized cellulase were observed at $\mathrm{pH}$ 5.0, as shown in Figure 6a. The immobilized cellulase showed a significant higher relative activity than that of free cellulase at $\mathrm{pH}$ from 3.0 to 6.0. It is noted that the relative activity of immobilized cellulase was approximately two-fold higher than those of free cellulase at $\mathrm{pH}$ 3.0 4.0. Figure $6 \mathrm{~b}$ shows the effect of temperature on the activity of immobilized and free cellulase. The optimal temperature $\left(50{ }^{\circ} \mathrm{C}\right)$ of the immobilized enzyme was the same as the free cellulase. The immobilized cellulase displayed relative higher activities at the temperature range from 30 to $80^{\circ} \mathrm{C}$ when compared with the free cellulase. The kinetic parameters $\mathrm{K}_{\mathrm{m}}$ of the immobilized and free cellulase were calculated with nonlinear regression as shown in Figure 7, and they were $2.19 \mathrm{~g} \mathrm{~L}^{-1}$ and $3.84 \mathrm{~g} \mathrm{~L}^{-1}$, while $\mathrm{V}_{\max }$ were $0.27 \mathrm{~g} \mathrm{~L}^{-1} \mathrm{~min}^{-1}$ and $0.23 \mathrm{~g} \mathrm{~L}^{-1} \mathrm{~min}^{-1}$, respectively. The thermal stability and reusability as important parameters for immobilized cellulase were investigated at $50{ }^{\circ} \mathrm{C}$ within $3 \mathrm{~h}$, and the results were shown in Figures 8 and 9. As shown in Figure 8, the relative activity of free and immobilized decreased with the increase of incubation time, the activity of free cellulase decreased sharply than that of the immobilized cellulase. When the incubation time was raised to 3 $\mathrm{h}$, the immobilized cellulase remained above $85 \%$ of its original activity, while the free cellulase was only $67 \%$ of its original activity. The thermal deactivation constant $(\mathrm{kd})$ of the immobilized cellulase (0.013) was six-fold lower than that of the free enzyme (0.078). The values of half-lives for the free and immobilized cellulase were $533 \mathrm{~min}$ and $89 \mathrm{~min}$, respectively. There is a five-fold improvement than that of the free cellulase. The reusability of the immobilized enzyme was checked, as shown in Figure 9. It still had $90 \%$ and $80 \%$ residual activities after four and nine reaction cycles, respectively. 

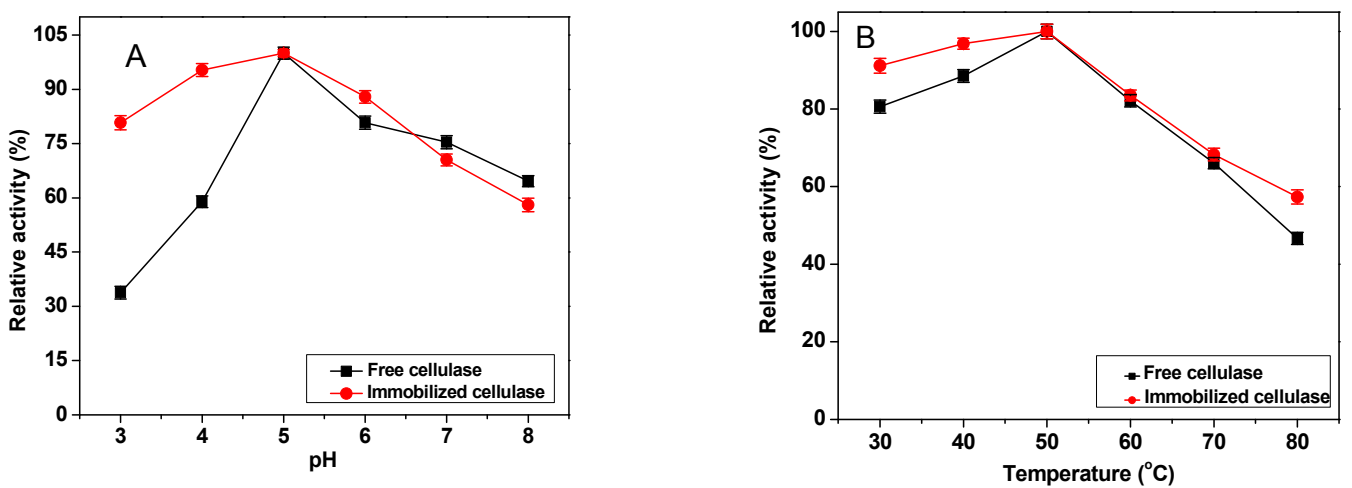

Figure 6. Effects of $\mathrm{pH}$ value (A) and temperature (B) on the activity of free (square) and immobilized cellulase (circle).

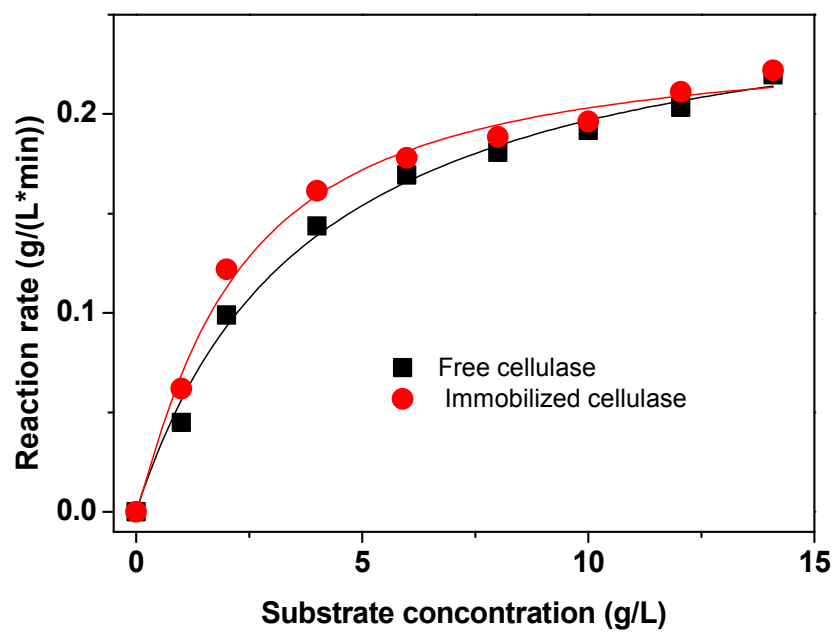

Figure 7. Effect of reaction rate on the substrate concentration of free cellulase (square) and immobilized cellulase (circle).

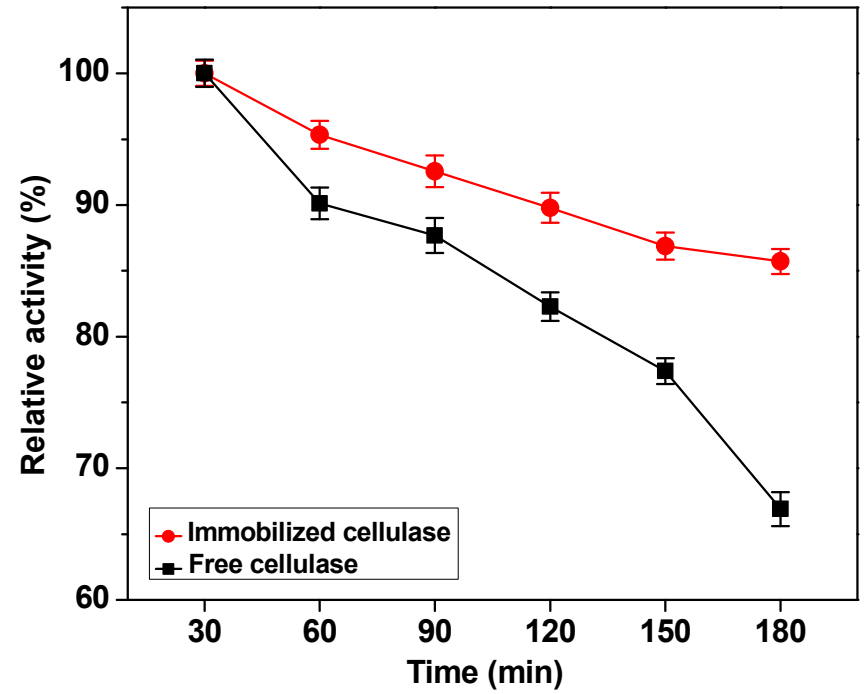

Figure 8. The thermal stability of free cellulase (square) and immobilized (circle) at $50^{\circ} \mathrm{C}$. 


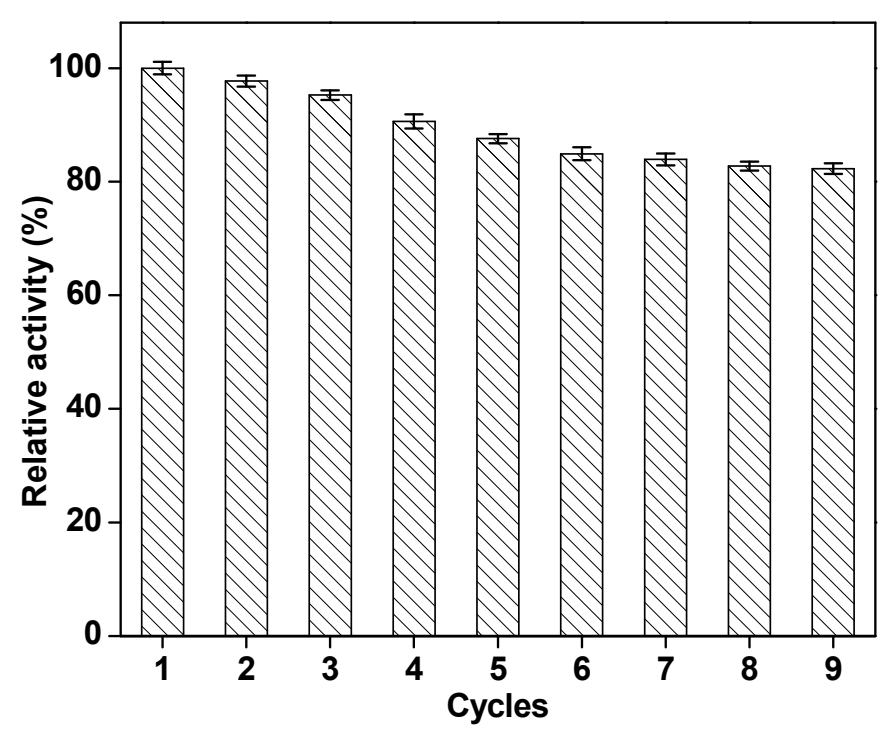

Figure 9. The reusability of the immobilized cellulase.

\section{Discussion}

Immobilization of enzymes has received wide attention because of the high cost of enzymes. It is well known that GO contained epoxy, carbonyl, and hydroxyl groups [27] and the modification is easier than other nanoparticles [28-33]. In our previous work, GO derivatives were used as the carrier for immobilization of cellulose [2] and NADH oxidase [22], and the immobilized enzyme retain higher stability and good reusability. In the present work, functionalized GO was prepared by etherification and diazotization (Scheme 1). The changes of FTIR peaks indicated that GO was successful prepared and activated. Subsequently, cellulase was covalently coupled onto the functionalized $\mathrm{GO}$, and the factors, including $\mathrm{pH}$, initial concentration of protein and immobilization time were optimized. A high immobilization yield and activity recovery of above $90 \%$ were achieved. When compared with the free enzyme, the immobilized cellulase displayed high relative activity in a wide range of $\mathrm{pH}$, especially $\mathrm{pH} 3-5$. It might be induced by covalent immobilization that fixed the configuration of enzyme on the surface of supports, resulting in the tolerability of cellulase to $\mathrm{pH}$ in surroundings increased [34]. In addition, owing to the unique properties of functionalized GO, such as high surface area and more binding-sites, the microenvironment of the immobilization process could have been buffered [35]. When compared with free enzyme, the lower $K_{m}$ and the higher $V_{\max }$ demonstrated the high binding affinity to substrates. The higher relative enzyme activity for immobilized cellulase would be due to the hydrophobic spacer SESA. The proper length and hydrophobic property of the spacer would restrict the immobilized enzyme mobile range and improve the mobile frequency, and thus the immobilized showed higher substrate binding affinity. Another reason for this phenomenon probably is that the activated GO has many hydrophilic groups on the surface that could enrich substrates nearby, and this will present more chances for substrate to bind enzymes.

The immobilized cellulase showed higher relative activity at higher temperatures. It is possible because the functional GO has high special surface area, thermal tolerance, and mechanical hardness. These properties would increase the stabilization of cellulase and could keep its active structure even at a higher temperature [36]. The very good reusability of immobilized cellulase makes the process catalyzed by cellulase much economic. A higher residual activity after reusing was because of the strong covalent bonds between the enzyme molecules and the prepared carrier. The decrease in immobilized enzyme activity was possibly caused by several reasons including unavoidable enzyme deactivation during repeated operation and batch separation.

As an important factor affected the productivity and the economic benefit in the industrial production, the immobilization time was investigated. It is interesting that the immobilization yield reached 90\% within $10 \mathrm{~min}$. Comparison with the previous reports [7,37-39] (as shown in Table 1), 
the immobilization of cellulase is in this work is quite quick and efficient. The reason might be the contribution of hydrophilic groups of GO and the hydrophobic spacer.

Table 1. Comparison of different carrier for covalent immobilization of cellulase.

\begin{tabular}{cccccc}
\hline Carrier & Spacer & $\begin{array}{c}\mathrm{Km}^{-1} \\
\left(\mathbf{g ~ L}^{-1}\right)\end{array}$ & Stability & Immobilization Time & Reference \\
\hline Clay composite materials & - & - & 1.4 & $8 \mathrm{~h}$ & {$[39]$} \\
polyacrylate amphiphilic copolymer & carbodiimide & 120.89 & 1.2 & $4 \mathrm{~h}$ & {$[7]$} \\
polyamidoamine dendrimer-grafted silica & glutaraldehyde & 0.33 & 2.2 & $2 \mathrm{~h}$ & {$[37]$} \\
PVA membrane & - & - & - & $1 \mathrm{~h}$ & {$[38]$} \\
Graphene oxide & SESA & 2.17 & 2.1 & $10 \mathrm{~min}$ & This work \\
\hline
\end{tabular}

${ }^{1}$ Folds compared to the free counterpart.

In summary, graphene oxide was prepared and modified with SESA for immobilization for cellulase. The immobilization of cellulase was very fast and finished in $10 \mathrm{~min}$. The preparation process is simple and a high activity recovery (above $90 \%$ ) was obtained. In comparison with the free cellulase, the immobilized enzyme showed higher affinity to substrate. Furthermore, the good reusability and high thermal stability of immobilized cellulase make them rather charming for industrial applications.

\section{Materials and Methods}

\subsection{Materials}

Cellulase was obtained from Runyang Co. Ltd. (Wuxi, China). P- $\beta$-sulfuric acid ester ethyl sulfone aniline (SESA) was purchased from Sigma-aldrich (St. Louis, MO, USA). Bovine serum albumin from Bio-Rad (Hercules, CA, USA) was used as the standard protein. Carboxyl methyl cellulose (CMC) salt (medium viscosity), graphite powder, sodium nitrite, and the other chemicals were biotechnological or analytical reagents from Sinopharm (Shanghai, China).

\subsection{Preparation of Functional Graphene Oxide}

The synthesis of graphene oxide (GO) via a slight modified method developed by Hummers and Offerman [40]. Briefly, suspended $1 \mathrm{~g}$ of graphite powder in $25 \mathrm{~mL}$ sulfuric acid (98\%) under ice bath, and then added $\mathrm{NaNO}_{3}(1 \mathrm{~g})$ and $\mathrm{KMnO}_{4}(3 \mathrm{~g})$, respectively. The resultant suspension was vigorous stirred and cooled, so as to maintain the temperature of the mixture under $20^{\circ} \mathrm{C}$. Then, the mixture was heated to $35^{\circ} \mathrm{C}$ and was stirred $30 \mathrm{~min}$. The reaction temperature was increased to $90{ }^{\circ} \mathrm{C}$ and followed by slowly adding $50 \mathrm{~mL}$ of distilled water and stirred $1 \mathrm{~h}$. To stop the oxidation reaction, 40 $\mathrm{mL}$ of distilled water and $3 \mathrm{~mL}$ of $30 \%$ hydrogen peroxide solution were added sequentially. Then, the mixture was filtered, and washed with double-distilled water. The product was then resuspended in double-distilled water, and ultrasonicated $5 \mathrm{~min}$. The resultant nanoparticles were collected by centrifugation and drying $24 \mathrm{~h}$ at $40^{\circ} \mathrm{C}$ under vacuum.

To successfully obtain the immobilized enzyme via covalent immobilization, the carrier was activated primarily via etherification and diazotization. In brief, dissolve $0.5 \mathrm{~g}$ SESA in $6 \mathrm{~mL}$ deionized water. The $\mathrm{pH}$ was adjusted to 7.0 at $40{ }^{\circ} \mathrm{C}$ using $1.0 \mathrm{M} \mathrm{Na}_{2} \mathrm{CO}_{3}$. Added $0.5 \mathrm{~g}$ of $\mathrm{GO}$ into the above solution with stirring, and adjusted the $\mathrm{pH}$ to 13.0 with $0.5 \mathrm{M} \mathrm{NaOH}$ solution. In order to obtain the SESA-GO, the mixture was subjected to heat $30 \mathrm{~min}$ at $100^{\circ} \mathrm{C}$ and then washed twice with $0.05 \mathrm{M} \mathrm{NaOH}$ solution and deionized water, respectively. Subsequently, SESA-GO was suspended in $5 \mathrm{~mL}$ distilled water, and then $2.5 \mathrm{~mL} \mathrm{HCl}(1 \mathrm{M})$ and $2.5 \mathrm{~mL} \mathrm{NaNO} 2(5 \%)$ were added simultaneously. The reaction was sustained $30 \mathrm{~min}$ under ice bath for finishing the diazotization. The resultant was washed three times with $0.05 \mathrm{M} \mathrm{HCl}$ and dried $12 \mathrm{~h}$ with vacuum drier.

Characterization of the prepared particles with Fourier transform infrared (FTIR) spectra was performed with a spectrometer (FT-IR, Thermo NicoletAVATAR-370, Waltham, MA, USA) using the $\mathrm{KBr}$ pellet technique. The morphology of materials was observed with Transmission electron microscopy (TEM, Philips Tecnai 12, Holland). 


\subsection{Immobilization of Cellulase}

Dispersed $50 \mathrm{mg}$ modified carrier in $0.7 \mathrm{~mL}$ citrate buffer $(0.1 \mathrm{M}, \mathrm{pH} 5.0)$, and added $0.3 \mathrm{~mL}$ buffers containing cellulase to start the immobilization. After $1 \mathrm{~h}$ reaction at room temperature, the immobilized cellulase was collected by centrifugation and washed three times with citrate buffer $(0.1$ $\mathrm{M} \mathrm{pH} \mathrm{5.0).} \mathrm{The} \mathrm{protein} \mathrm{concentration} \mathrm{of} \mathrm{the} \mathrm{supernatant} \mathrm{was} \mathrm{measured} \mathrm{by} \mathrm{the} \mathrm{Bradford} \mathrm{method} \mathrm{[41]}$ and the activity of immobilized cellulase was determined. The immobilization yield and activity recovery were calculated, as the follows:

$$
\text { Immobilization yield }=100 \times[(\varrho i-\varrho w-\varrho s) / \varrho i] ; \text { Activity recovery }=100 \times(\alpha \mathrm{i} / \alpha \mathrm{f})
$$

where $\mathrm{Q} i$ is the total protein of the crude enzyme preparation; ow and os are the protein content of wash solution and supernatant after immobilization, respectively; $\alpha \mathrm{i}$ is the total activity of the immobilized cellulase; and, $\alpha \mathrm{f}$ is the total activity of the free cellulase. All of the assays were performed in triplicate.

\subsection{Enzyme Assay}

The activity of cellulase was detected based on the amount of released glucose from CMC solution under the catalysis of cellulase. For free enzyme, $0.25 \mathrm{~mL}$ enzyme was pre-incubated $10 \mathrm{~min}$ at $50{ }^{\circ} \mathrm{C}$. Then, the mixture of $0.25 \mathrm{~mL}$ enzyme that was dissolved in acetate buffer (pH 5.0) and 0.5 $\mathrm{mL}$ substrate $(w / v=2 \%)$ were incubated at $50{ }^{\circ} \mathrm{C}$ for $10 \mathrm{~min}$. Then, added $3 \mathrm{~mL}$ DNS to the mixture and terminated the reaction by heating the mixture $5 \mathrm{~min}$ in boiled water. The produced reducing sugar was measured with a UV detector (UV-1800, Mapada instrument, Shanghai, China) at $540 \mathrm{~nm}$. For immobilized enzyme, $50 \mathrm{mg}$ of immobilized enzyme was pre-incubated $10 \mathrm{~min}$ at $50{ }^{\circ} \mathrm{C}$. Then, $0.5 \mathrm{~mL}$ of substrate was added into to react $10 \mathrm{~min}$. The reaction was terminated by adding $3 \mathrm{~mL}$ DNS and put into boiled water bath for $5 \mathrm{~min}$. After separation, the supernatant was subjected to determine the concentration of glucose to calculate the activity. One unit (U) of cellulase is defined as the amount of enzyme that hydrolyzes CMC in order to produce $1 \mathrm{mg}$ equivalent of glucose per minute under the assay conditions.

\subsection{Optimization of Immobilization Conditions}

The effect of $\mathrm{pH}$ on the immobilization was assessed over the range of $\mathrm{pH}$ (3.0-8.0). Similarly, the mixture of varying enzyme/support ratios from 1.9 to $8.7 \mathrm{mg} / \mathrm{g}$ in the $\mathrm{pH}$ range of 3.0 to 8.0 was reacted in the various time periods ranging from $1 \mathrm{~min}$ to $60 \mathrm{~min}$. After certain time intervals, the mixture was separated by centrifugation of $5 \mathrm{~min}$ at 12,000 rpm. Subsequently, the amount of the protein in the supernatant was determined. Each experiment was performed in triplicate. The optimization data are presented as the averages of statistically relevant measurements with their associated standard deviation.

\subsection{Characterization of the Immobilized Cellulase}

The effect of temperature on the activities of free and immobilized cellulase was evaluated by assaying the enzyme samples over the range of $30-80{ }^{\circ} \mathrm{C}$ for $10 \mathrm{~min}$. To check the effect of $\mathrm{pH}$, activities of immobilized and free cellulase were determined using the standard assay conditions with two buffer systems, citrate buffer $(0.1 \mathrm{M}, \mathrm{pH} 3.0,4.0,5.0)$ and phosphate buffer $(0.1 \mathrm{M}, \mathrm{pH}$ 6.0, $7.0,8.0)$. To determine maximum reaction rates $\left(\mathrm{V}_{\max }\right)$ and kinetic parameters $\left(\mathrm{K}_{\mathrm{m}}\right)$ of free and immobilized cellulase, the activity assays were performed in different CMC concentrations. Vmax and $\mathrm{Km}$ of cellulase was obtained by nonlinear regression.

The thermal stability of cellulase was investigated by incubating the free and immobilized enzyme from 30 to $180 \mathrm{~min}$ at optimal $\mathrm{pH}$ and at $50{ }^{\circ} \mathrm{C}$. At certain time intervals, samples were withdrawn, and residual activity was measured under standard assay conditions. The half-life ( $\left.\mathrm{t}_{1 / 2}\right)$ of cellulase at $50{ }^{\circ} \mathrm{C}$ was determined using the following equation:

$$
\mathrm{t} 1 / 2=0.693 / \mathrm{kd}^{2} \mathrm{kd}^{*} \mathrm{t}=\ln \left(\mathrm{E}_{0} / \mathrm{E}\right)
$$


where $\mathrm{E}_{0}$ is the initial cellulase activity, $\mathrm{E}$ is the residual cellulase activity after $\mathrm{t} \min$, and $\mathrm{kd}$ is the attenuation constant.

The reusability of immobilized cellulase was investigated at the optimal $\mathrm{pH}$ and temperature. Each sample was performed in triplicate. The characterization data are presented as the averages of statistically relevant measurements with their associated standard deviation.

Author Contributions: J.G. and Y.-W.Z. conceived and designed the experiments; J.G., C.-L.L., Y.W., S.-S.W. and J.-J.S. performed the experiments; J.G., C.-L.L. and Y.W. analyzed the data; J.G. and Y.-W.Z. wrote the paper. J.X.Z. instructed experiments design.

Acknowledgments: The authors appreciate the financial support from National Natural Science Foundation of China (No. 21376110) and Guangxi Natural Science Foundation (2016GXNSFCA380011).

Conflicts of Interest: The authors declare no conflict of interest.

\section{References}

1. Hamid, S.B.A.; Islam, M.M.; Das, R. Cellulase biocatalysis: Key influencing factors and mode of action. Cellulose 2015, 22, 2157-2182, doi:10.1007/s10570-015-0672-5.

2. Li, Y.; Wang, X.-Y.; Jiang, X.-P.; Ye, J.-J.; Zhang, Y.-W.; Zhang, X.-Y. Fabrication of graphene oxide decorated with $\mathrm{Fe}_{3} \mathrm{O}_{4} @ \mathrm{SiO}_{2}$ for immobilization of cellulase. J. Nanopart. Res. 2015, 17, 1-12, doi:10.1007/s11051-0142826-z.

3. Mubarak, N.M.; Wong, J.R.; Tan, K.W.; Sahu, J.N.; Abdullah, E.C.; Jayakumar, N.S.; Ganesan, P. Immobilization of cellulase enzyme on functionalized multiwall carbon nanotubes. J. Mol. Catal. B Enzym. 2014, 107, 124-131, doi:10.1016/j.molcatb.2014.06.002.

4. Zang, L.; Qiu, J.; Wu, X.; Zhang, W.; Sakai, E.; Wei, Y. Preparation of magnetic chitosan nanoparticles as support for cellulase immobilization. Ind. Eng. Chem. Res. 2014, 53, 3448-3454, doi:10.1021/ie404072s.

5. Ince, A.; Bayramoglu, G.; Karagoz, B.; Altintas, B.; Bicak, N.; Arica, M.Y. A method for fabrication of polyaniline coated polymer microspheres and its application for cellulase immobilization. Chem. Eng. J. 2012, 189-190, 404-412, doi:10.1016/j.cej.2012.02.048.

6. Cho, E.J.; Jung, S.; Kim, H.J.; Lee, Y.G.; Nam, K.C.; Lee, H.-J.; Bae, H.-J. Co-immobilization of three cellulases on Au-doped magnetic silica nanoparticles for the degradation of cellulose. Chem. Commun. 2011, 48, 886888, doi:10.1039/C2CC16661E.

7. Liang, W.; Cao, X. Preparation of a pH-sensitive polyacrylate amphiphilic copolymer and its application in cellulase immobilization. Bioresour. Technol. 2012, 116, 140-146, doi:10.1016/j.biortech.2012.03.082.

8. Li, Y.; Wang, X.-Y.; Zhang, R.-Z.; Zhang, X.-Y.; Liu, W.; Xu, X.-M.; Zhang, Y.-W. Molecular Imprinting and Immobilization of Cellulase onto Magnetic Fe3O4@SiO2 Nanoparticles. J. Nanosci. Nanotechnol. 2014, 14, 2931-2936, doi:10.1166/jnn.2014.8625.

9. Ling, X.-M.; Wang, X.-Y.; Ma, P.; Yang, Y.; Qin, J.-M.; Zhang, X.-J.; Zhang, Y.-W. Covalent immobilization of penicillin $\mathrm{G}$ acylase onto $\mathrm{Fe}_{3} \mathrm{O}_{4} @$ Chitosan magnetic nanoparticles. J. Microbiol. Biotechnol. 2016, 26, 829836, doi:10.4014/jmb.1511.11052.

10. Tao, Q.-L.; Li, Y.; Shi, Y.; Liu, R.-J.; Zhang, Y.-W.; Guo, J. Application of molecular imprinted magnetic $\mathrm{Fe}_{3} \mathrm{O}_{4} @ \mathrm{SiO}_{2}$ nanoparticles for selective immobilization of cellulase. J. Nanosci. Nanotechnol. 2016, 16, 60556060, doi:10.1166/jnn.2016.10853.

11. Zhuang, M.-Y.; Zhou, Q.-L.; Wang, X.-Y.; Zhang, J.-X.; Xue, L.; Wang, R.; Zhang, J.-X.; Zhang, Y.-W. Immobilization of lipase onto dopamine functionalized magnetic nanoparticles. Nanosci. Nanotechnol. Lett. 2016, 8, 251-254, doi:10.1166/nnl.2016.2127.

12. Zhuang, M.-Y.; Jiang, X.-P.; Ling, X.-M.; Xu, M.-Q.; Zhu, Y.-H.; Zhang, Y.-W. Immobilization of glycerol dehydrogenase and NADH oxidase for enzymatic synthesis of 1,3-dihydroxyacetone with in situ cofactor regeneration. J. Chem. Technol. Biotechnol. 2018, 93, doi:10.1002/jctb.5579.

13. Wang, X.-Y.; Jiang, X.-P.; Li, Y.; Zeng, S.; Zhang, Y.-W. Preparation Fe3 $\mathrm{O}_{4} @$ chitosan magnetic particles for covalent immobilization of lipase from Thermomyces lanuginosus. Int. J. Biol. Macromol. 2015, 75, 44-50, doi:10.1016/j.ijbiomac.2015.01.020.

14. Zhuang, M.-Y.; Wang, C.; Xu, M.-Q.; Ling, X.-M.; Shen, J.-J.; Zhang, Y.-W. Using concanavalinA as a spacer for immobilization of E. coli onto magnetic nanoparticles. Int. J. Biol. Macromol. 2017, 104, 63-69, doi:10.1016/j.ijbiomac.2017.05.150. 
15. Liu, W.; Zhou, F.; Zhang, X.-Y.; Li, Y.; Wang, X.-Y.; Xu, X.-M.; Zhang, Y.-W. Preparation of magnetic $\mathrm{Fe}_{3} \mathrm{O}_{4} @ \mathrm{SiO}_{2}$ nanoparticles for immobilization of lipase. J. Nanosci. Nanotechnol. 2014, 14, 3068-3072, doi:10.1166/jnn.2014.8567.

16. Chowdhury, S.; Balasubramanian, R. Graphene/semiconductor nanocomposites (GSNs) for heterogeneous photocatalytic decolorization of wastewaters contaminated with synthetic dyes: A review. Appl. Catal. B Environ. 2014, 160-161, 307-324, doi:10.1016/j.apcatb.2014.05.035.

17. Lee, H.; Jeong, H.K.; Han, J.; Chung, H.-S.; Jang, S.-H.; Lee, C. Increased thermal stability of cold-adapted esterase at ambient temperatures by immobilization on graphene oxide. Bioresour. Technol. 2013, 148, 620623, doi:10.1016/j.biortech.2013.09.018.

18. Mani, V.; Devasenathipathy, R.; Chen, S.-M.; Huang, S.-T.; Vasantha, V.S. Immobilization of glucose oxidase on graphene and cobalt phthalocyanine composite and its application for the determination of glucose. Enzyme Microb. Technol. 2014, 66, 60-66, doi:10.1016/j.enzmictec.2014.08.009.

19. Gokhale, A.A.; Lu, J.; Lee, I. Immobilization of cellulase on magnetoresponsive graphene nano-supports. J. Mol. Catal. B Enzym. 2013, 90, 76-86, doi:10.1016/j.molcatb.2013.01.025.

20. Liu, J.; Wang, T.; Wang, J.; Wang, E. Mussel-inspired biopolymer modified 3D graphene foam for enzyme immobilization and high performance biosensor. Electrochim. Acta 2015, 161, 17-22, doi:10.1016/j.electacta.2015.02.034.

21. Wang, J.; Zhao, G.; Jing, L.; Peng, X.; Li, Y. Facile self-assembly of magnetite nanoparticles on threedimensional graphene oxide-chitosan composite for lipase immobilization. Biochem. Eng. J. 2015, 98, 75-83, doi:10.1016/j.bej.2014.11.013.

22. Liu, C.-H.; Li, X.-Q.; Jiang, X.-P.; Zhuang, M.-Y.; Zhang, J.-X.; Bao, C.-H.; Zhang, Y.-W. Preparation of functionalized graphene oxide nanocomposites for covalent immobilization of NADH oxidase. Nanosci. Nanotechnol. Lett. 2016, 8, 164-167, doi:10.1166/nnl.2016.2102.

23. Andre, J.; Saleh, D.; Syldatk, C.; Hausmann, R. Effect of spacer modification on enzymatic synthetic and hydrolytic activities of immobilized trypsin. J. Mol. Catal. B Enzym. 2016, 125, 88-96, doi:10.1016/j.molcatb.2016.01.003.

24. Nouaimi, M.; Moschel, K.; Bisswanger, H. Immobilization of trypsin on polyester fleece via different spacers. Enzyme Microb. Technol. 2001, 29, 567-574, doi:10.1016/S0141-0229(01)00429-X.

25. Deere, J.; De Oliveira, R.F.; Tomaszewski, B.; Millar, S.; Lalaouni, A.; Solares, L.F.; Flitsch, S.L.; Halling, P.J. Kinetics of enzyme attack on substrates covalently attached to solid surfaces: Influence of spacer chain length, immobilized substrate surface concentration and surface charge. Langmuir 2008, 24, 11762-11769, doi:10.1021/la801932f.

26. Du, T.; Liu, B.; Hou, X.; Zhang, B.; Du, C. Covalent immobilization of glucose oxidase onto Poly(St-GMANaSS) monodisperse microspheres via BSA as spacer arm. Appl. Surf. Sci. 2009, 255, 7937-7941, doi:10.1016/j.apsusc.2009.04.172.

27. Hu, Y.; Wang, K.; Zhang, Q.; Li, F.; Wu, T.; Niu, L. Decorated graphene sheets for label-free DNA impedance biosensing. Biomaterials 2012, 33, 1097-1106, doi:10.1016/j.biomaterials.2011.10.045.

28. Xiong, F.; Hu, K.; Yu, H.; Zhou, L.; Song, L.; Zhang, Y.; Shan, X.; Liu, J.; Gu, N. A functional iron oxide nanoparticles modified with PLA-PEG-DG as tumor-targeted MRI contrast agent. Pharm. Res. 2017, 34, 1683-1692, doi:10.1007/s11095-017-2165-8.

29. Xie, M.; Xu, Y.; Shen, H.; Shen, S.; Ge, Y.; Xie, J. Negative-charge-functionalized mesoporous silica nanoparticles as drug vehicles targeting hepatocellular carcinoma. Int. J. Pharmaceut. 2014, 474, 223-231, doi:10.1016/j.ijpharm.2014.08.027.

30. Shen, S.; Wu, L.; Liu, J.; Xie, M.; Shen, H.; Qi, X.; Yan, Y.; Ge, Y.; Jin, Y. Core-shell structured Fe3 $\mathrm{O}_{4} @ \mathrm{TiO}_{2}-$ doxorubicin nanoparticles for targeted chemo-sonodynamic therapy of cancer. Int. J. Pharmaceut. 2015, 486, 380-388, doi:10.1016/j.ijpharm.2015.03.070.

31. Zhu, T.; Tao, Z.; Jia, L.; Luo, Y.-F.; Xu, J.; Chen, R.-H.; Ge, Z.-J.; Ma, T.-L.; Chen, H. Multifunctional nanocomposite based on halloysite nanotubes for efficient luminescent bioimaging and magnetic resonance imaging. Int. J. Nanomed. 2016, 11, 4765-4776, doi:10.2147/IJN.S110081.

32. Ali, S.; Morsy, R.; El-Zawawy, N.; Fareed, M.; Bedaiwy, M. Synthesized zinc peroxide nanoparticles (ZnO2NPs): a novel antimicrobial, anti-elastase, anti-keratinase, and anti-inflammatory approach toward polymicrobial burn wounds. Int. J. Nanomed. 2017, 12, 6059-6073, doi:10.2147/IJN.S141201. 
33. Liu, H.; Shi, S.; Cao, J.; Ji, L.; He, Y.; Xi, J. Preparation and evaluation of a novel bioactive glass/lysozyme/PLGA composite microsphere. Drug Dev. Ind. Pharm. 2015, 41, 458-463, doi:10.3109/03639045.2013.877485.

34. Mateo, C.; Palomo, J.M.; Fernandez-Lorente, G.; Guisan, J.M.; Fernandez-Lafuente, R. Improvement of enzyme activity, stability and selectivity via immobilization techniques. Enzyme Microb. Technol. 2007, 40, 1451-1463, doi:10.1016/j.enzmictec.2007.01.018.

35. Li, T.; Li, S.; Wang, N.; Tain, L. Immobilization and stabilization of pectinase by multipoint attachment onto an activated agar-gel support. Food Chem. 2008, 109, 703-708, doi:10.1016/j.foodchem.2008.01.012.

36. Tang, T.; Fan, H.; Ai, S.; Han, R.; Qiu, Y. Hemoglobin (Hb) immobilized on amino-modified magnetic nanoparticles for the catalytic removal of bisphenol A. Chemosphere 2011, 83, 255-264, doi:10.1016/j.chemosphere.2010.12.075.

37. Wang, S.; Su, P.; Ding, F.; Yang, Y. Immobilization of cellulase on polyamidoamine dendrimer-grafted silica. J. Mol. Catal. B-Enzym. 2013, 89, 35-40, doi:10.1016/j.molcatb.2012.12.011.

38. Wu, L.L.; Yuan, X.Y.; Sheng, J. Immobilization of cellulase in nanofibrous PVA membranes by electrospinning. J. Membr. Sci. 2005, 250, 167-173, doi:10.1016/j.memsci.2004.10.024.

39. Bayramoglu, G.; Senkal, B.F.; Arica, M.Y. Preparation of clay-poly(glycidyl methacrylate) composite support for immobilization of cellulase. Appl. Clay Sci. 2013, 85, 88-95, doi:10.1016/j.clay.2013.09.010.

40. Hummers, W.S., Jr.; Offeman, R.E. Preparation of graphitic oxide. J. Am. Chem. Soc. 1958, 80, 1339-1339.

41. Bradford, M.M. A rapid and sensitive method for the quantitation of microgram quantities of protein utilizing the principle of protein-dye binding. Anal. Biochem. 1976, 72, 248-254, doi:10.1016/00032697(76)90527-3.

(C) 2018 by the authors. Licensee MDPI, Basel, Switzerland. This article is an open access article distributed under the terms and conditions of the Creative Commons Attribution (CC BY) license (http://creativecommons.org/licenses/by/4.0/). 